\title{
Epidemiological Study of Japanese Encephalitis Virus in Vientiane, Lao PDR, in 1990s
}

\author{
Mika Saito, ${ }^{1}$ Douangdao Soukaloun, ${ }^{2}$ Khampe Phongsavath, ${ }^{3}$ \\ Bounlay Phommasack, ${ }^{4}$ and Yoshihiro Makino ${ }^{5}$ \\ ${ }^{1}$ Department of Microbiology and Oncology, Graduate School of Medicine, University of the Ryukyus, \\ 207 Uehara, Nishihara, Okinawa 903-0215, Japan \\ ${ }^{2}$ Department of Pediatrics, Mahosot Hospital, Mahosot Road, 01030 Vientiane, Laos \\ ${ }^{3}$ Department of Pediatrics, Setthathirath Hospital, Boulevard Kamphengmeuang, 01030 Vientiane, Laos \\ ${ }^{4}$ Department of Communicable Disease Control, Ministry of Health, Si Mouang Road, 01030 Vientiane, Laos \\ ${ }^{5}$ Shimane Environment \& Health Public Corporation, 1-4-6, Koshihara, Matsue, Shimane 690-0012, Japan \\ Correspondence should be addressed to Mika Saito; mikas@med.u-ryukyu.ac.jp
}

Received 3 October 2014; Accepted 16 December 2014

Academic Editor: Rajesh Jeewon

Copyright (C) 2015 Mika Saito et al. This is an open access article distributed under the Creative Commons Attribution License, which permits unrestricted use, distribution, and reproduction in any medium, provided the original work is properly cited.

\begin{abstract}
Phylogenetic analysis of Japanese encephalitis virus (JEV) was conducted using core-premembrane and envelope gene sequence data of two strains from Vientiane, Lao People's Democratic Republic, in 1993 and five from Okinawa, Japan, in 2002 and 2003 , and previously published strains. The two Vientiane strains designated as LaVS56 and LaVS145 belonged to genotype 1 (G1) and the same subcluster of G1 as Australian strain in 2000, Thai strains in 1982-1985 and 2004-2005, and Vietnamese strain in 2005, but were distinct from the subcluster of recently distributing G1 strains widely in Asia including Okinawan strains and recent Lao strain in 2009. These clusters with own distinct distributions indicated involvements of different mechanisms and routes of spreading viruses and clarified that Australian G1 strain is from Southeast Asia, not from East Asia. Both Vientiane strains were antigenically close to P19-Br (G1, isolate, Thailand), but distinct from Nakayama (G3, prototype strain, Japan), Beijing-1 (G3, laboratory strain, China), and JaGAr\#01 (G3, laboratory strain, Japan), demonstrated by cross-neutralization tests using polyclonal antisera. These results together with seroepidemiologic study conducted in Vientiane strongly suggest that diversified JEV cocirculated there in early 1990s.
\end{abstract}

\section{Introduction}

Japanese encephalitis (JE) is a feared disease with a high mortality rate and grave sequelae in the form of neurological and mental impairments [1]. The pathogen responsible for the disease, Japanese encephalitis virus (JEV), belongs to the Flavivirus genus of the family Flaviviridae, a singlestranded positive-sense RNA virus, which includes emerging and reemerging pathogens such as West Nile virus and dengue viruses $[2,3]$. The genome of JEV is approximately 11,000 bases in length and encodes 3 structural proteins (C: capsid, PrM: premembrane, and E: envelope proteins) and 7 nonstructural proteins (NS1, NS2A, NS2B, NS3, NS4A, NS4B, and NS5). JEV is transmitted to humans by vector mosquitoes from vertebrates, with pigs usually acting as the principal viremic host, and birds, particularly ardeid species, serving as maintenance reservoirs in the wild $[2,4]$. Culex tritaeniorhynchus is the most efficient vector and breeds in bodies of stagnant water such as paddy fields [5].

Five genotypes of JEV based on structure protein sequences, with geographically distinct distributions, have been described [6-8]. Genotype 2 (G2) has been isolated in Southern Thailand, Malaysia, Papua New Guinea (PNG), and Northern Australia, with one strain recognized in the Republic of Korea (ROK) prior to 1951 [9]. Genotype 3 (G3) has been widely distributed throughout Asia. Genotype 4 (G4) has only been isolated in Indonesia between 1980 and 1981 [7]. Only one Singapore strain from 1951 had been recognized as genotype 5 (G5), but it recently reemerged in China and ROK after more than 50 years [10-12]. 
Before the 1990s, genotype 1 (G1) was distributed in a limited area, from Northern Thailand to Cambodia. It has since moved into Vietnam, China, ROK, Japan, Taiwan, and even Australia, mostly via the so-called genotype-shift phenomenon, whereby a preexisting genotype disappears and is supplanted by another genotype [13-17]. This phenomenon was suggested not to be caused by the intensity of selection $[12,18]$. Migratory birds, winds capable of carrying vector insects, travel, and transport are believed to have important roles in the spread of emerging genotypes to new territories; however, the mechanisms involved remain unclear [4].

Lao PDR is a landlocked country situated on the Indochinese peninsula. Geographically, the Annamite Range and the Mekong River lie on its borders, separating the country from Thailand and Vietnam. Only a little information about JE in Lao PDR is available. Okuno [19] first described 34 seasonal encephalitis cases possibly caused by JEV in 1974 . Several seroepidemiological studies were conducted on JE in Lao PDR in the 1990s and 2000s [20-25]. An endemic pattern was discovered by studies in which prevalence rates of JE antibodies increased gradually with age in residents and changed seasonally in slaughtered swine in the 1990s [21]. Mackenzie et al. [4] speculated that the low numbers of reported cases were due to a lack of accurate indications and the absence of good surveillance. According to recent reports, an epidemic of JE is occurring [26], with about 50 cases diagnosed serologically between 2001 and 2008 at the largest hospitals in Vientiane [27]. Vaccination programme now includes JE vaccine using SA14-14-2 strains in Lao PDR.

The genetics of JEV is well studied in Lao's neighbors Thailand and Vietnam, which had epidemics of JE during the 1990s, with G1 and G3 as the major genotypes, respectively, but not in Lao PDR. After a case of the genotype-shift phenomenon, namely, G3 to G1 in Vietnam, the major subclusters of G1 Vietnamese and Thai strains were different [28]. Recently, the complete sequence of a JEV isolate from a patient in 2009 in Lao PDR was reported [29]; however, antigenic and genetic analyses of JEV were not described.

In the present study, we sequenced the C/PrM and $\mathrm{E}$ protein regions of two JEV isolates from swine sera collected in Vientiane, Lao PDR, in 1993, and analyzed those of isolates phylogenetically by comparison with sequenced G1 Okinawan strains and previously published sequence data of strains from different regions and periods, as well as antigenically by cross-neutralization testing and seroepidemiologically. The possible routes of JEV spread and coexistence of diverse forms of JEV strains in Vientiane, Lao PDR, are discussed.

\section{Material and Methods}

2.1. Cell Culture. The mosquito Aedes albopictus clone C6/36 cell line was grown at $28^{\circ} \mathrm{C}$ with Eagle's minimum essential medium (MEM) supplemented with seven nonessential amino acids and $8 \%$ heat-inactivated fetal bovine serum (FBS). Baby hamster kidney-21 (BHK-21) and African green monkey kidney (Vero) cell clones were grown at $37^{\circ} \mathrm{C}$ in $8 \%$ FBS-Eagle's MEM as growth medium. All cell clones were maintained with 2\% FBS-Eagle's MEM as maintenance medium in a $5 \% \mathrm{CO}_{2}$ atmosphere when the virus isolation and neutralization test were being conducted.

2.2. Collection of Serum Samples. A total of 641 swine serum samples were collected monthly in 1993 and 1994, from domestically reared pigs at a private slaughterhouse in Vientiane Municipality of Lao PDR [21].

Human serum samples from 45 viral encephalitissuspected patients were collected at acute and convalescent phases in 1994 at two of the largest hospitals in Vientiane. Samples from 8 patients confirmed to have JE in Chiang Mai, Thailand, in 1991 were kindly supplied by Associate Professor Sittisombut, Chiang Mai University. Samples from 2 confirmed cases of JE in Okinawa in 1991 were also used [30]. A total of 278 serum samples from children under 13 years old were collected at the Ministry of Health kindergarten and Paxai Primary School, both in the Sisattanak District, located in an urban area of Vientiane, from January to March (dry season), 1994.

Antisera against 5 strains of JEV, Nakayama (a prototype and vaccine strain, Tokyo, Japan, human brain, 1935, G3), Beijing-1 (a laboratory and vaccine strain, Beijing, China, human brain, 1949, G3), P19-Br (an isolate, Chiang Mai, Thailand, human brain, 1982, G1), LaVS56 (an isolate, Vientiane, Lao PDR, swine sera, 1993, G1), and LaVS145 (an isolate, Vientiane, Lao PDR, swine sera, 1993, G1), were prepared in $\mathrm{BALB} / \mathrm{c}$ mice as described previously [31]. Before serologic testing, sera were inactivated at $56^{\circ} \mathrm{C}$ for 30 minutes.

2.3. Isolation and Identification of Viruses. A total of 196 among 641 swine serum samples that tested negative for JE antibodies in an IgG ELISA [21,32] were tested for the virus. The virus isolation and identification procedure were as described previously $[15,33]$.

2.4. Sequences. Two hundred and forty nucleotides of the core-premembrane $(\mathrm{C} / \mathrm{PrM})$ gene region and 1500 nucleotides of the envelope (E) gene region of two Vientiane JEV isolates and the $\mathrm{E}$ region of five Okinawan isolates, Oki 431S, Oki 128S, Oki 568S, Oki 585S, and Oki 589S, were sequenced (Table 1). Viral RNA was extracted from a JEVinfected C6/36 cell culture by using an RNeasy Mini Kit (Qiagen, Hilden, Germany) or QIAamp Viral RNA Mini Kit (Qiagen) according to the manufacturer's instructions. RTPCR was performed using the QIAGEN OneStep RT-PCR Kit (Qiagen) also according to the manufacturer's instructions. RT-PCR products were purified using a QIAamp MinElute column (Qiagen) or MinElute Gel Extraction Kit (Qiagen). The products were then sequenced with a BigDye Terminator v.1.1 or v.3.1 cycle sequence kit (Applied Biosystems) and further purified using a DyeEx 2.0 Spin Kit (Qiagen). The sequencing reactions were analyzed on an ABI PRISM 310 and 3100 DNA sequencer (Applied Biosystems). The primers referred to previous publications $[14,34]$.

2.5. Nucleic Acid Sequence Analysis. Details of all the JEV strains used in the phylogenetic analysis are listed in Table 1. 
TABLE 1: JEV isolates analyzed in this study.

\begin{tabular}{|c|c|c|c|c|c|c|}
\hline \multirow{2}{*}{ Strain } & \multirow{2}{*}{ Year } & \multirow{2}{*}{ Location } & \multirow{2}{*}{ Source } & \multirow{2}{*}{ Genotype } & \multicolumn{2}{|c|}{ Accession number } \\
\hline & & & & & $\mathrm{C} / \mathrm{PrM}$ & $\mathrm{E}$ \\
\hline Nakayama & 1935 & Tokyo, Japan & Human brain & 3 & U03694 & S75726 \\
\hline Beijing-1 & 1949 & Beijing, China & Human brain & 3 & L48961 & L48961 \\
\hline P20778 & 1958 & Vellore, India & Human brain & 3 & AF080251 & AF080251 \\
\hline JaGAr\#01 & 1959 & Gunma, Japan & C. tritaeniorhynchus & 3 & D00961 & AF069076 \\
\hline M-859 & 1967 & Cambodia & C. gelidus & 1 & D00984 & U70410 \\
\hline WTP/70/22 & 1970 & Kuala Lumpur, Malaysia & Mosquito & 2 & D00998 & U70421 \\
\hline M28 & 1977 & Yunnan, China & C. pseudovishnui & 1 & JF706279 & JF706279 \\
\hline Th2372 & 1979 & Thailand & Human brain & 1 & D76424 & U70401 \\
\hline VN-118 & 1979 & Ho Chi Minh, Vietnam & C. fatigans & 3 & D00975 & U70420 \\
\hline JKT7003 & 1981 & Indonesia & Mosquito & 4 & L42161 & U70408 \\
\hline JKT9092 & 1981 & Indonesia & Mosquito & 4 & L42158 & U70409 \\
\hline JKT5441 & 1981 & Indonesia & Mosquito & 2 & L42164 & U70406 \\
\hline $\mathrm{P} 19-\mathrm{Br}$ & 1982 & Chiang Mai, Thailand & Human brain & 1 & D76427 & JEU70416 \\
\hline B-0860/82 & 1982 & Thailand & Pig & 1 & GQ902058 & GQ902058 \\
\hline $1070 / 82$ & 1982 & Thailand & Human & 1 & GQ902059 & GQ902059 \\
\hline JaOArS982 & 1982 & Japan & Mosquito pool & 3 & M18370 & M18370 \\
\hline YN83-Meng83-54 & 1983 & Yunnan, China & Lasiohelea taiwana Shiraki & 1 & DQ404062 & DQ404130 \\
\hline YN83-83199 & 1983 & Yunnan, China & Culex sp. & 1 & DQ404063 & DQ404131 \\
\hline PhAn 1242 & 1984 & Santo Cristo, Philippines & Swine blood & 3 & D00982 & U70417 \\
\hline B-2239 & 1984 & Chiang Mai, Thailand & Swine blood & 1 & D00993 & U70391 \\
\hline B-1381-85 & 1985 & Thailand & Pig & 1 & GQ902061 & GQ902061 \\
\hline 3KP“U”CV569 & 1985 & Thailand & Mosquito & 1 & GQ902060 & GQ902060 \\
\hline $4790-85$ & 1985 & Thailand & Human & 1 & GQ902062 & GQ902062 \\
\hline YN85-L86-99 & 1985 & Yunnan, China & Culex sp. & 1 & DQ404064 & DQ404132 \\
\hline Naha Meat 54 & 1985 & Okinawa, Japan & Swine blood & 3 & D85958 & DQ355367* \\
\hline YN86-B8639 & 1986 & Yunnan, China & C. tritaeniorhynchus & 1 & DQ404065 & DQ404133 \\
\hline YN86-86266 & 1986 & Yunnan, China & NA & 1 & DQ404066 & DQ404134 \\
\hline ThCMAr4492 & 1992 & Chiang Mai, Thailand & mosquito & 1 & D45360 & D45362 \\
\hline ThCMAr6793 & 1993 & Chiang Mai, Thailand & C. tritaeniorhynchus & 1 & D45361 & D45363 \\
\hline LaVS56 & 1993 & Vientiane, Lao PDR & Swine serum & 1 & GQ850124* & GU815346* \\
\hline LaVS145 & 1993 & Vientiane, Lao PDR & Swine serum & 1 & GQ850123* & GU815345* \\
\hline K94P05 & 1994 & Korea & C. tritaeniorhynchus & 1 & AF045551 & AF045551 \\
\hline Ishikawa & 1997 & Ishikawa, Japan & Swine mononuclear cell & 1 & AB051292 & AB051292 \\
\hline Okinawa/1 & 1998 & Okinawa, Japan & Wild boar & 1 & NA & AB306941 \\
\hline KV1899 & 1999 & Korea & NA & 1 & AY316157 & AY316157 \\
\hline TS00 & 2000 & Australia & Swine serum & 1 & AF289814 & EF434785 \\
\hline SH-53 & 2001 & Shanghai, China & C. tritaeniorhynchus & 1 & AY555746 & AY555757 \\
\hline VN88 & 2001 & Vietnam & Swine blood & 1 & NA & AY376464 \\
\hline LN02-102 & 2002 & Liaoning, China & C. modestus & 1 & DQ404018 & DQ404085 \\
\hline Oki 431S & 2002 & Okinawa, Japan & Swine serum & 1 & DQ355361 & DQ355369* \\
\hline MIE-41 & 2002 & Mie, Japan & Swine serum & 1 & NA & AB112709 \\
\hline SIZUOKA-39 & 2002 & Shizuoka, Japan & Swine serum & 1 & NA & AB112704 \\
\hline KAGAWA-27 & 2002 & Kagawa, Japan & Swine serum & 1 & NA & AB112707 \\
\hline Oki $128 S$ & 2003 & Okinawa, Japan & Swine serum & 1 & DQ355362 & DQ355368* \\
\hline Oki 568S & 2003 & Okinawa, Japan & Swine serum & 1 & DQ355363 & DQ355370* \\
\hline Oki 585S & 2003 & Okinawa, Japan & Swine serum & 1 & DQ355364 & DQ355371* \\
\hline Oki 589S & 2003 & Okinawa, Japan & Swine serum & 1 & DQ355365 & DQ355372* \\
\hline JE-NP-R7 & 2003 & Thailand & Swine blood & 1 & DQ084216 & DQ084228 \\
\hline
\end{tabular}


TABle 1: Continued.

\begin{tabular}{|c|c|c|c|c|c|c|}
\hline \multirow{2}{*}{ Strain } & \multirow{2}{*}{ Year } & \multirow{2}{*}{ Location } & \multirow{2}{*}{ Source } & \multirow{2}{*}{ Genotype } & \multicolumn{2}{|c|}{ Accession number } \\
\hline & & & & & $\mathrm{C} / \mathrm{PrM}$ & $\mathrm{E}$ \\
\hline JE-CP-49 & 2004 & Chumphon, Thailand & Swine blood & 1 & DQ084223 & DQ087974 \\
\hline JE-CP-51 & 2004 & Chumphon, Thailand & Swine blood & 1 & DQ084225 & DQ087973 \\
\hline JE-CP-67 & 2004 & Chumphon, Thailand & Swine blood & 1 & DQ084222 & DQ087972 \\
\hline JE-KK-R87 & 2004 & Khon Kaen, Thailand & Swine blood & 1 & DQ084218 & DQ111788 \\
\hline JE-KK-R88 & 2004 & Khon Kaen, Thailand & Swine blood & 1 & DQ084219 & DQ111786 \\
\hline LA-H06-05 & 2005 & Vietnam & mosquitoes & 1 & NA & FJ185153 \\
\hline LA.M-2.3 & 2005 & Vietnam & C. pseudovishnui & 1 & NA & JN574432 \\
\hline JE-CM-1196 & 2005 & Chiang Mai, Thailand & Swine & 1 & DQ356483 & DQ238602 \\
\hline JE-KK-580 & 2005 & Khon Kaen, Thailand & Swine & 1 & DQ356481 & DQ238600 \\
\hline JE-KK-1116 & 2005 & Khon Kaen, Thailand & Swine & 1 & DQ388999 & DQ343290 \\
\hline VNHT/07/2006 & 2006 & Ha Tai, Vietnam & C. tritaeniorhynchus & 1 & NA & AB728498 \\
\hline JaNAr17-07 & 2007 & Nagasaki, Japan & mosquitoes & 1 & NA & FJ185149 \\
\hline GSBY0861 & 2008 & Gansu, China & C. tritaeniorhynchus & 1 & JN381833 & JN381833 \\
\hline 09P141 & 2009 & Oita, Japan & Swine & 1 & NA & GU108335 \\
\hline YN0967 & 2009 & Yunnan, China & C. tritaeniorhynchus & 1 & JF706268 & JF706268 \\
\hline JEV/CNS769 & 2009 & Vientiane, Laos & Human brain & 1 & KC196115 & KC196115 \\
\hline
\end{tabular}

NA: not available, ${ }^{*}$ sequenced in this study.

Multiple alignments and the phylogenetic analysis were performed by the neighbor-joining (NJ) method using Clustal-X [35]. The bootstrap probabilities of each node were calculated using 1000 replicates. All of the phylogenetic trees were drawn using the NJplot program [36]. For phylogeographic analysis, a map JEV G1 was drawn with published data based on sequences of the E protein, except for Malaysian isolates for the $\mathrm{C} / \mathrm{PrM}$ region [37].

2.6. Serologic Test. For serological analysis of human sera from acute encephalitis cases, six JEV strains (Nakayama, Beijing-1, JaGAr\#01, P19-Br, LaVS56, and LaVS145), four prototype strains of dengue virus type 1 (Hawaiian), 2 (New Guinea B), 3 (H-87), and 4 (H-241), and a strain of WNV (Eg101) were used for fifty percent focus-reduction neutralization tests, as described previously [15].

For the antigenic analysis using mouse antisera, crossneutralization tests against Nakayama, Beijing-1, JaGAr\#01, P19-Br, LaVS56, and LaVS145 were conducted.

For the seroepidemiological analysis using sera obtained from children, neutralization tests against Nakayama, Beijing-1, and LaVS145 were employed. Sera positive for neutralizing antibodies against any of the three strains were used for the comparison of neutralization reactivity. Neutralizing antibody titers against three strains were plotted in correlation graphs. Pearson's correlation coefficient was used for paired values. A statistical analysis of Pearson's correlation coefficient was conducted using the $t$-test.

\section{Results}

3.1. Phylogenetic Analysis. Two strains of virus, LaVS56 and LaVS145, were recovered from serum samples of slaughtered swine collected on May 27 and October 4, 1993, respectively, in Vientiane, Lao PDR. Both strains were identified as belonging to genotype 1 (G1) of JEV from nucleotide sequences of the $\mathrm{C} / \mathrm{PrM}$ and $\mathrm{E}$ gene regions (Table 1 and Figure 1).

Phylogenetic trees of C/PrM and E have similar construction, without contradiction between genotypes and clusters. Percent homologies of the two Vientiane strains are $98.3 \%$ at the nucleotide level and $98.8 \%$ at the amino acid level in $\mathrm{C} / \mathrm{PrM}$ and $96.6 \%$ at the nucleotide level and $99.0 \%$ at the amino acid level in the E region. All of the 6 Okinawan G1 isolates ( 5 in this study and one published) created a unique Okinawan cluster based on the E region.

According to Nitatpattana et al. [38], LaVS56 and LaVS145 belonged to a subcluster, Gla, corresponding to Lineage 1, the oldest lineage among G1 according to a study by Gao et al. [39] (Figure 1(b)). Further analysis based on the E region revealed LaVS145 to be closely related to strain LA.M-2.3, isolated in Vietnam in 2005, to TS00, isolated in Northern Australia in 2000, and to Thai strains, isolated between 1982 and 1985. LaVS56 was also closely related to Thai isolates from 2004 and 2005. LaVS56 and LaVS145 belonged to different genetic groups within Gla. The G1b subcluster, by contrast, comprised isolates from East and Southeast Asia [28], including a recent Lao strain from 2009, and Okinawan G1 strains.

The distribution of subclusters of G1, namely, Gla and G1b, is shown in Figure 2. The G1 strains between 1967 and 1990 were distributed in a limited area on the Indochinese peninsula, but since then, Gla and Glb have been introduced into geographically distinct regions. Before 1990, Gla was distributed from Yunnan, China, to Northern Thailand and Cambodia, while G1b was recognized only in Yunnan. During the 1990s, the distribution of each cluster expanded, with Gla spreading into Lao PDR, Malaysia, and Australia, while G1b spread into Thailand and to the east into ROK and Japan, including Okinawa. The situation of G1 during the 1990s in 


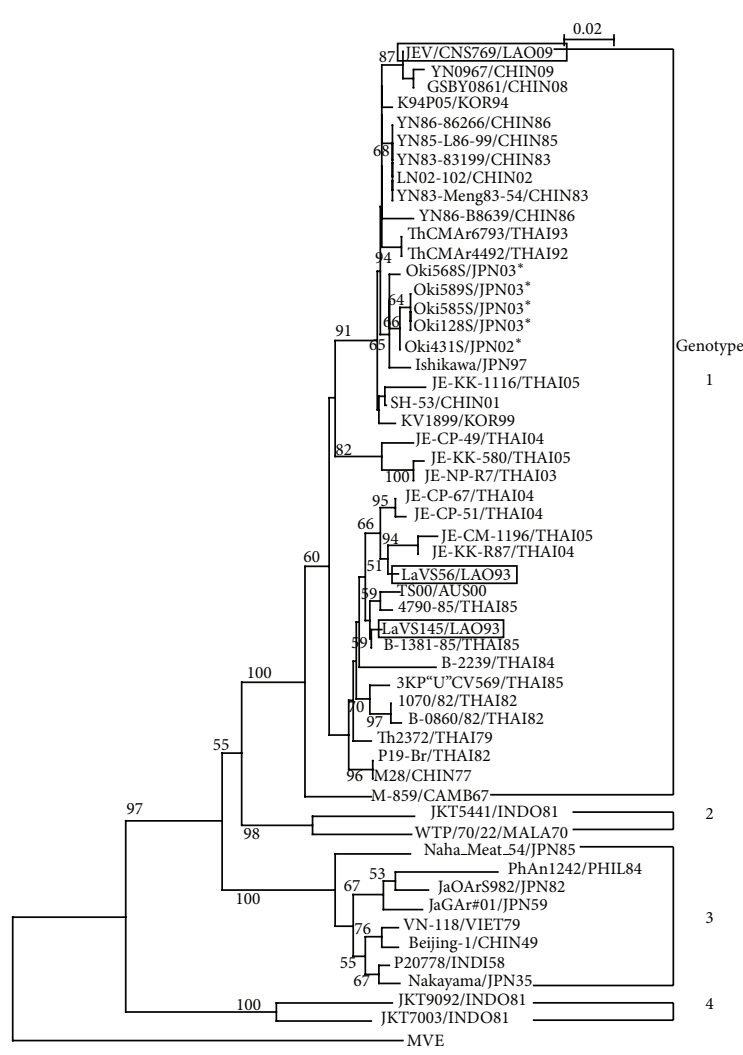

(a)

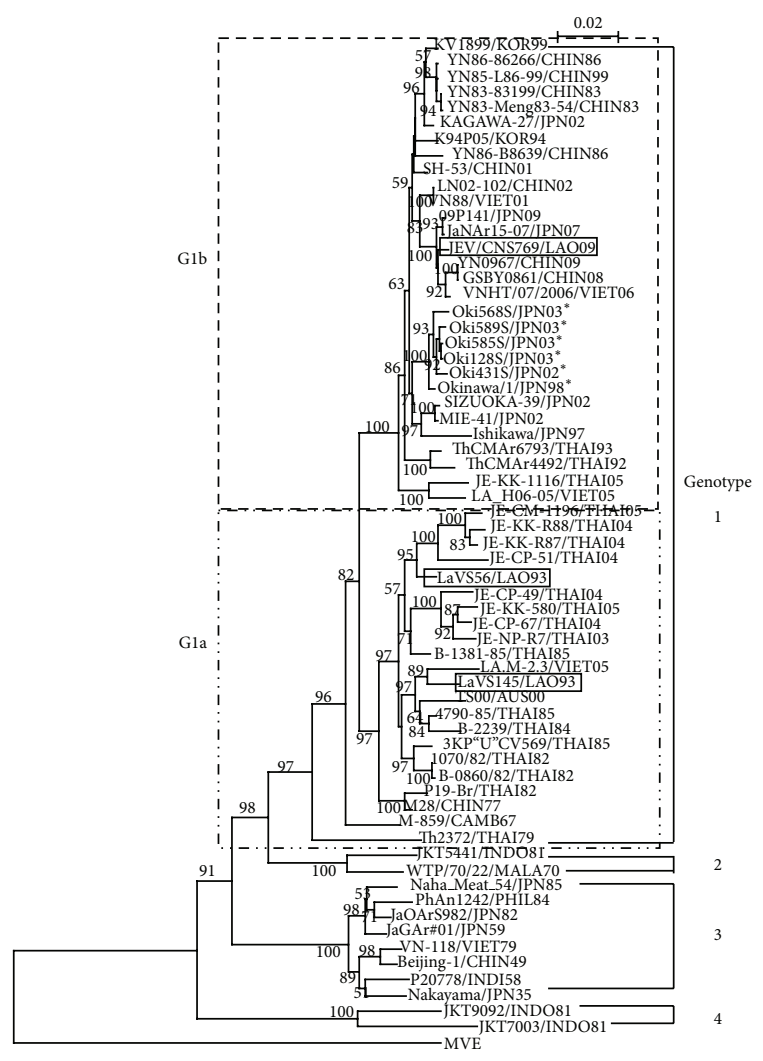

(b)

FIGURE 1: Phylogenetic analysis of JEV strains, with the Murray Valley encephalitis virus strain MVE 1-51 (GenBank accession number NC-000943) as an outgroup. (a) Tree based on a 240-nucleotide sequence of the core-premembrane gene region. (b) Tree based on a 1500nucleotide sequence of the envelope gene region. Vientiane isolates are indicated in the box, and Okinawan isolates are indicated as *. Gla subcluster and G1b subcluster of JEV genotype 1, indicated in the dot line box, according to Nitpattana and others (2008).

inland and coastal China remained unknown. After 2000, Gla was found limited in Northeast and Southern Thailand and Vietnam, while Glb was isolated from widespread Asian regions, such as Vietnam, Northeast Thailand, Lao PDR, Northern India, Yunnan, Tibet, inland and coastal China, ROK, Taiwan, and Japan including Okinawa $[15-17,28$, 3844].

This map probably indicates that the Australian G1 isolate, Gla, in 2000 originated from Southeast Asia, such as from Cambodia, Yunnan, Thailand, Lao PDR, and Malaysia through the Sunda Islands, and not from East Asia, such as China and Japan through Okinawa, Taiwan, and the Philippines, where Gla strains had not been isolated. This map supports the hypothesis that Indochina, the southernmost Asian region, was the source of JEV transmission to the Asian countries for both Gla and Glb [39].

\subsection{Antigenic Characterization of Two Vientiane Isolates.} Both of the Vientiane isolates in 1993 were antigenically characterized by cross-neutralization testing using antisera against 5 JEV strains: two strains representative of established antigenic subtypes, namely, Nakayama (prototype, vaccine and laboratory strain, G3) and Beijing-1 (vaccine and laboratory strain, G3), a previously characterized strain: $\mathrm{P} 19-\mathrm{Br}$
(Chiang Mai isolate, G1) [31, 45], and two Vientiane isolates: LaVS56 and LaVS145 (Figure 3(a)). Nakayama and Beijing1 were antigenically distinguishable from each other. The Nakayama and Beijing- 1 antisera neutralized the homologous strains, while the titers to the heterologous strains were about 10- to 1000-fold lower. The reactivity of the antisera against P19-Br, LaVS56, and LaVS145 behaved in a similar way, indicating that both Vientiane strains belong to the same antigenic group as $\mathrm{P} 19-\mathrm{Br}$, as previously described for the ThCAr6793 subtype by Ali and Igarashi [31]. Namely, these sera of the $\mathrm{P} 19-\mathrm{Br}$ group neutralized Nakayama, Beijing1, JaGAr\#01 (the same antigenic group as Beijing-1), P19$\mathrm{Br}$, LaVS56, and LaVS145 as homologous strains, suggesting the presence of a broader cross-neutralizing epitope in the antigenic domain.

3.3. Serologic Characteristics of JE Patients in Three Regions. Forty-five cases clinically diagnosed as viral encephalitis were admitted to the largest two hospitals, Mahosot and Sethathirath Hospitals, in Vientiane, Lao PDR in 1994. Among them, two patients, code numbers 25 and 37, were serologically diagnosed with JE, and another two patients were diagnosed with dengue encephalopathy by neutralization tests and IgMcaptured ELISA for JE and dengue (data not shown). A total 




G1a

O G1b

(a)

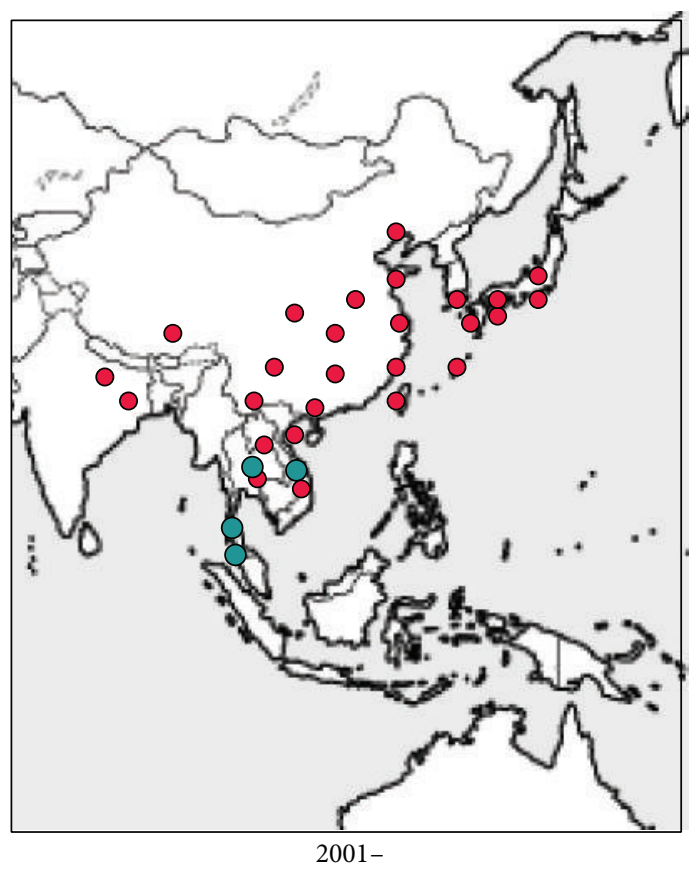

(c)

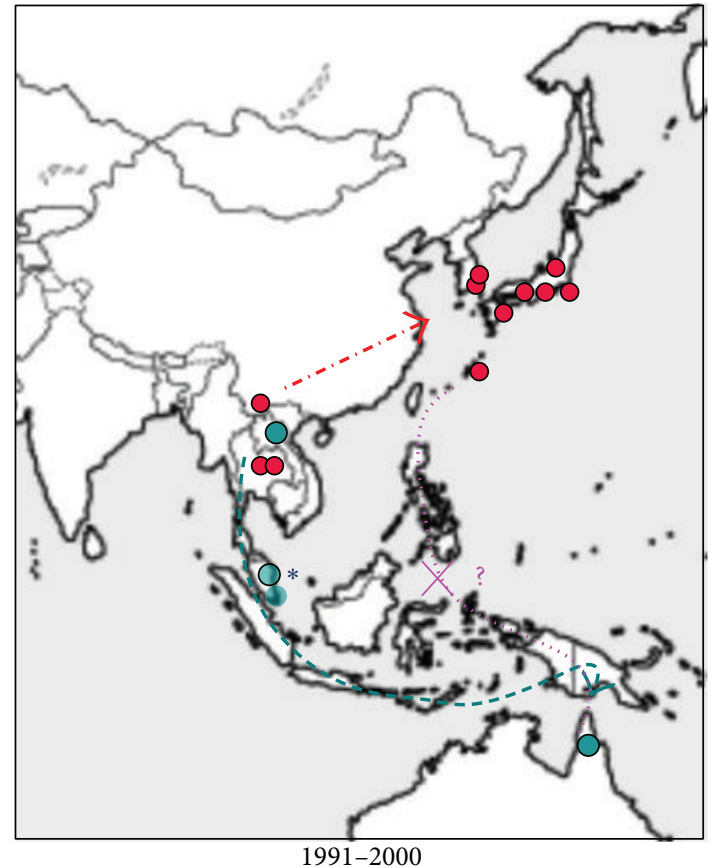

* Sequence of $\mathrm{E}$ region was not available, estimated G1a based on C/PrM region

(b)

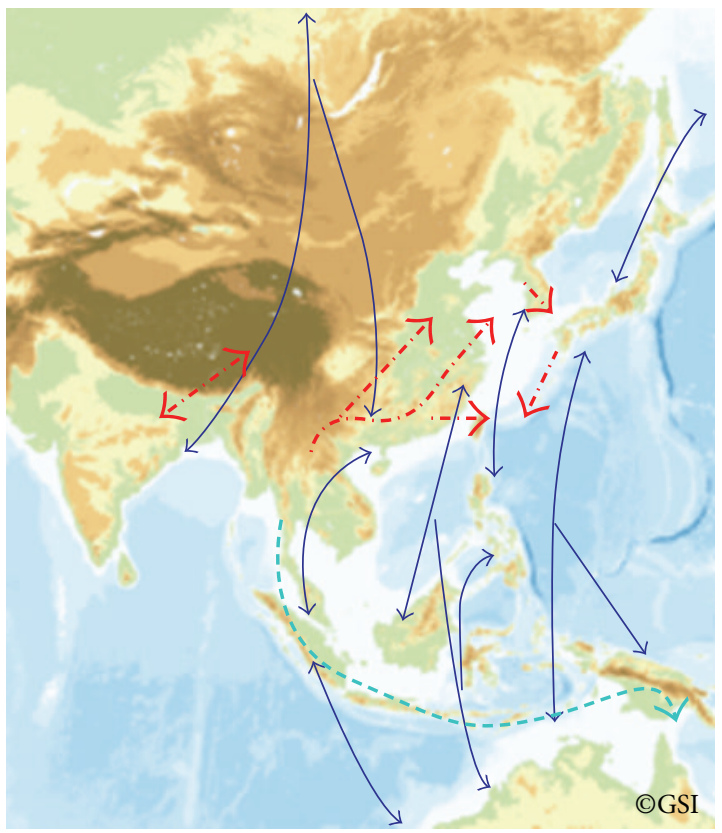

East Asian-Australasian flyway of migratory birds

$\longleftrightarrow$ East Asian-

$\rightarrow$ Australasian flyway

$\Rightarrow$ Estimated route of G1a spread

-.) Estimated route of G1b spread

(d)

FIGURE 2: The distribution of subclusters of genotype 1 JEV in each time period, 1967-1990, 1991-2000, and 2001-. The blue dots represent Gla and red dots G1b represent isolates analyzed in this study and published strains. The lower right panel shows an altitude map with the East Asian-Australasian flyways of migration cited from http://www.ozcoasts.gov.au/indicators/shorebird_counts.jsp and estimated migration routes of Gla and Glb. 

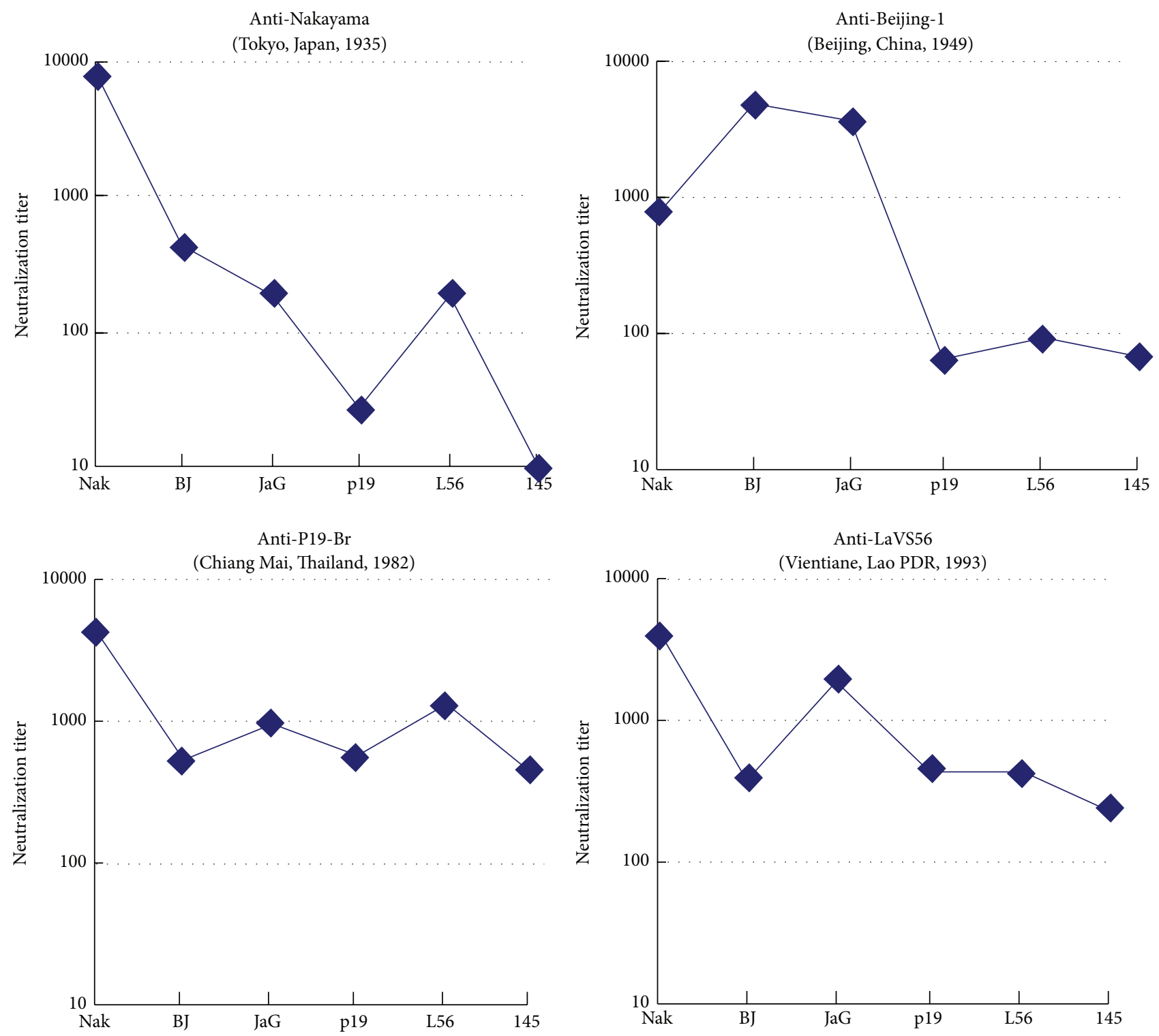

Anti-LaVS145

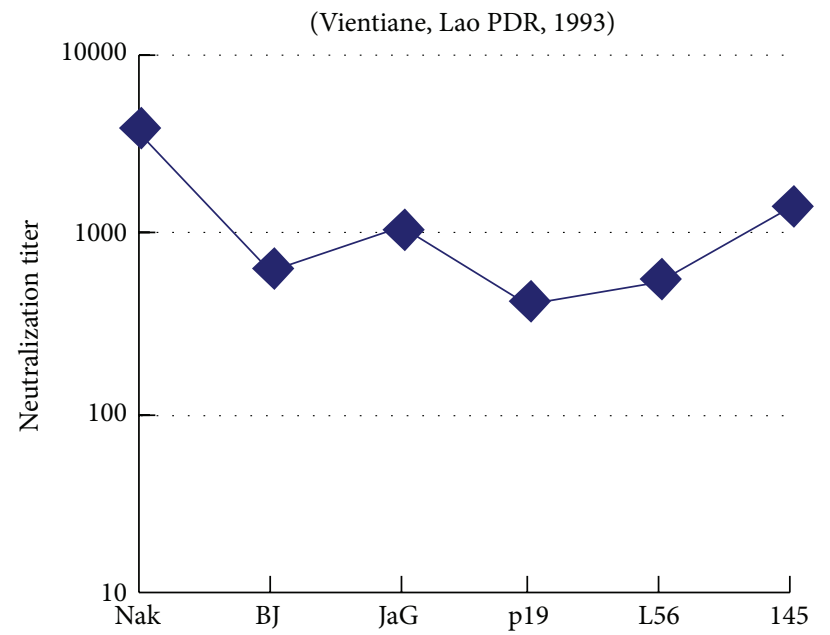

(a)

Figure 3: Continued. 

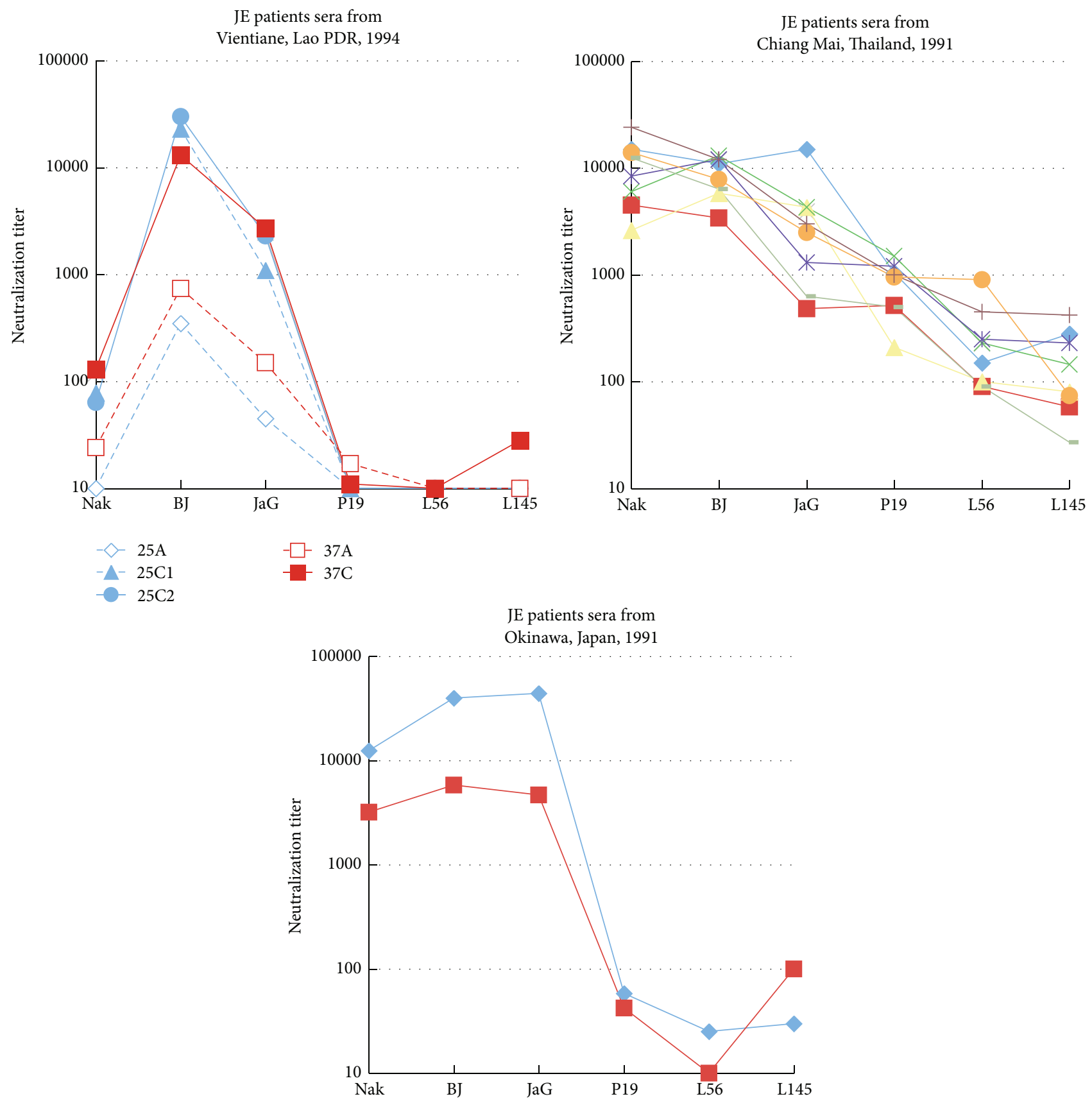

(b)

FIGURE 3: (a) Cross-neutralization testing on 6 JEV strains using polyclonal mouse antisera inoculated with different JEV strains: Nakayama, Beijing-1, P19-Br, LaVS56, and LaVS145. Vertical line: neutralizing antibody titers against JEV strains: Nakayama (Nak), Beijing-1 (BJ), JaGAr\#01 (JaG), P19-Br (P19), LaVS56 (L56), and LaVS145 (L145) in a $\log _{10}$ scale. (b) The reactivity of sera from JE patients of different regions: two cases of JE (A: acute sera, C: convalescent sera) from Vientiane, Lao PDR, in 1994; eight cases from Chiang Mai, Thailand, in 1991; and two cases from Okinawa, Japan, in 1991. Vertical line: neutralizing antibody titers against JEV strains as panel (a).

of 41 cases had an unknown etiology. This result together with previous seroepidemiological data [20-22] suggests that Lao PDR was a JE-endemic country early in the 1990s. Interestingly, the sera of both JE patients showed a significant increase of more than 4-fold between acute and convalescent sera in terms of the neutralizing antibody titers against Beijing-1 (vaccine strain, G3), JaGAr\#01 (laboratory strain,
G3), and Nakayama (vaccine strain, G3), but not against P19Br (G1, Chiang Mai, Thailand), LaVS145 (G1, Vientiane, Lao PDR), or LaVS56 (G1, Vientiane, Lao PDR) (Figure 3(b)). In addition, convalescent-phase sera from eight JE patients in Chiang Mai, Thailand, in 1991 and two JE patients in Okinawa, Japan, in 1991 showed unique neutralization patterns in each area (Figure 3(b)). The serum samples from Chiang 

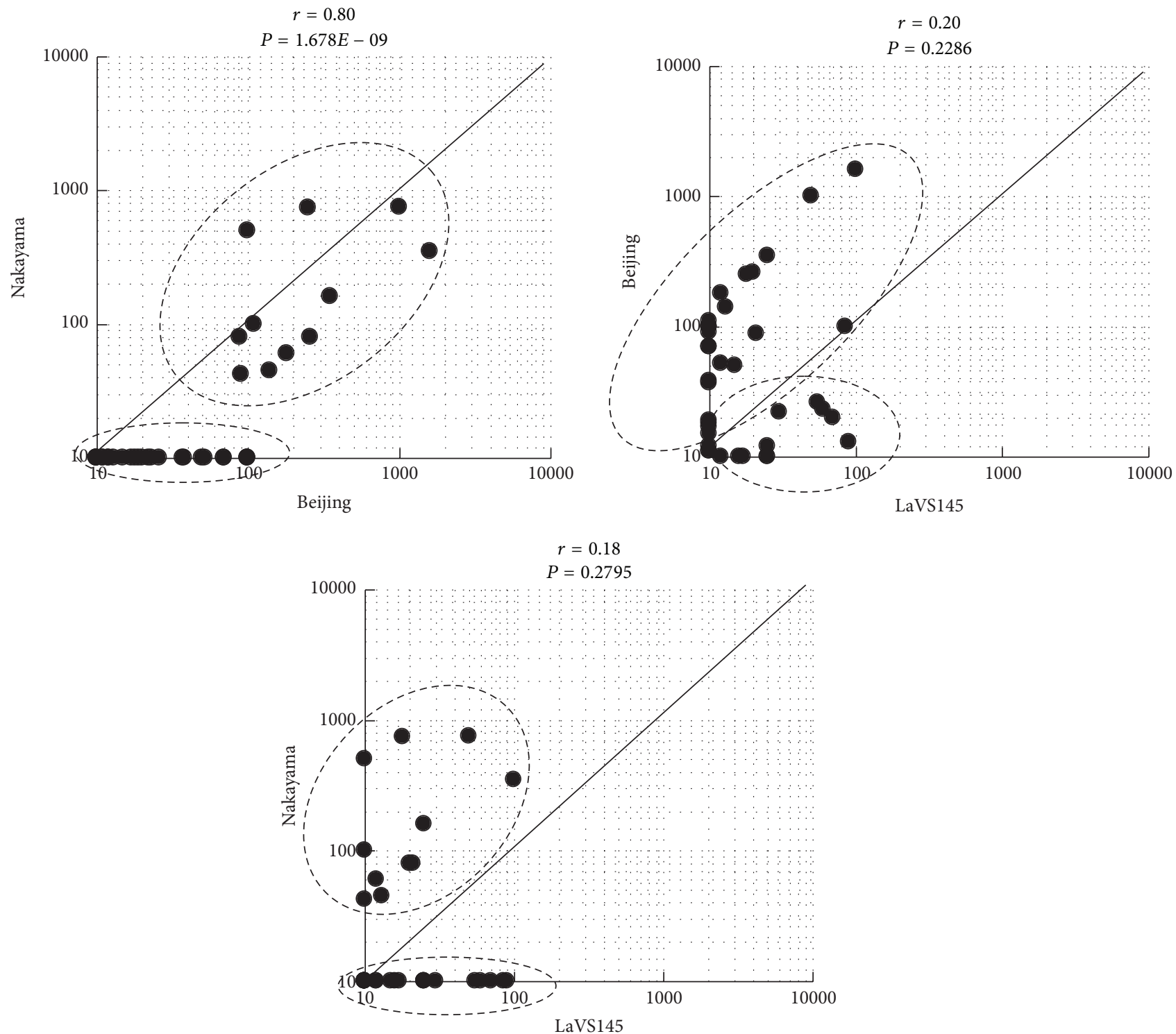

FIGURE 4: Correlation graphs of neutralizing antibody titers against three strains of Japanese encephalitis virus in children in Vientiane in 1994, between JEV strains. The $x$ - and $y$-axes show neutralization titers against each strain. The correlation coefficient is described as an $r$ value. The result of a $t$-test for each correlation coefficient is shown as a $P$ value.

Mai reacted with the Chiang Mai, Vientiane, and laboratory strains. The samples from Okinawa had similar neutralization patterns to those from Vientiane and the antisera for Beijing1 that rarely reacted with Vientiane and Chiang Mai strains. On the other hand, the samples from Chiang Mai had similar patterns to the antisera for P19-Br, LaVS56, and LaVS145. JE patients in Vientiane seemed to be infected with the Beijing-1 serogroup, not the P19-Br serogroup.

\subsection{Neutralization Reactivity in Healthy Children in Vientiane.} Since vaccination programs in Lao PDR did not include the JE vaccine in 1990s, the presence of the JE antibody in children may reflect the natural transmission of JEV. Among 278 serum samples taken from children under 13 years old in Vientiane in 1994, 38 had antibodies against any of the 3 JEV strains, Nakayama, Beijing-1, and LaVS145
(Figure 4). The samples tended to be divided into two groups: those that neutralized Nakayama or Beijing-1 strongly and those that neutralized LaVS145 strongly. The coefficients of the relationships between Beijing-1 and LaVS145 and between Nakayama and LaVS145 were low and not significant $(P>0.1)$.

\section{Discussion}

To our knowledge, this is the report on the earliest JEV isolates from Vientiane in Lao PDR. Phylogeographic analysis of JEV G1 strains including Vientiane and Okinawan strain elucidated different clusters, Gla and Glb, with distinct distribution, evidenced that there are different mechanisms and routes to spread JEV G1 into new area, and proposed that the Australian Gla isolate originated from Thailand and 
Lao PDR region, Southeast Asia, but not from East Asia though Okinawa, Taiwan, probably through Philippines. The recent expansion of G1 in Asian countries has mainly involved G1b. Our data also support the view of Gao et al. [39] that Indochina, the southernmost Asian region, was the source of JEV transmission to the Asian countries.

Although both distributions correlate with East AsianAustralasian flyways of migratory birds [13, 39, 46, 47], the direction of spreading clusters is different; Gla is from north to south, while G1b is from west to east. Mackenzie et al. [48] hypothesized that JEV reached Australasia by island hopping across the eastern Indonesia archipelago by birds, particularly ardeid birds, establishing the bird-mosquito and pig-mosquito transmission cycles on each island as it moved. Ritchie and Rochester [49] calculated mosquitoes that could carry virus from PNG to islands in northern Australia during cyclonic weather patterns. On the other hand, Nabeshima et al. [28] and Morita [50] suggested that jet wind and westerly wind carrying small insects might be involved in G1 spread to East Asia beside migratory birds. Further study on the present situation of JEV in Indonesia and the Philippines will give us the clear map for the routes of expansion.

It was also believed that JEV was carried northward to and within Japan [51], since yearly seasonal activity of JEV had been started from Okinawa as southern-most area of Japan. The recent appearance of Glb in Taiwan has been about $600 \mathrm{~km}$ southwest from Okinawa Island, approximately 10 years after its first appearance in China, ROK, and Japan [40]. The Taiwanese G1 strains are related to strains in coastal China more than to those in Japan. Phylogenetic analysis suggested that JEV has been introduced into Okinawa from the north, such as ROK and other parts of Japan, and a serosurvey of migratory birds in Okinawa [52] suggests that it has been possibly carried by winter visitors.

The antigenic and genetic variation of JEV has been studied extensively. Nakayama and Beijing-1, both belonging to the G3 subgroup, are known to differ in antigenicity [4]. Antigenic variation was also reported within G1. The two Vientiane strains were of the same antigenic serogroup as P19Br and ThCMAr6793, according to Ali and Igarashi [31], most commonly observed in G1 by cross-neutralization testing, characterized by antisera that neutralize a wide range of JEV strains including members of not only homologous antigenic groups but also distinct antigenic groups, while antisera of Nakayama and Beijing-1 neutralize specifically homologous serogroups. The immune status of G3 in humans and pigs might have exerted pressure for genotype shift because of this difference.

Interestingly, sera from JE patients in Vientiane showed Beijing-1-type seroreactivity, similar to the antiserum of Beijing-1 and JE patients in Okinawa, Japan, in 1991, but different from the antisera for LaVS56, LaVS145, and P19-Br, and JE patients in Chiang Mai, Thailand, exhibited P19-Brtype seroreactivity. Only G3 had been isolated in Okinawa until 1992. These results indicate that the patients in Vientiane were infected by the Beijing-1 serogroup. Therefore, there were at least two different antigenic groups, Beijing-1-type and P19-Br-type, of JEV in Vientiane. Furthermore, the seroepidemiological study of healthy children in Vientiane strengthened the notion that there was a distinct antigenic group of JEV.

As no JEV G1 strains were reported to belong to the Beijing-1 serogroup, G1 and G3 may have coexisted in Vientiane in the early 1990s. In addition, the Vientiane strains, LaVS56 and LaVS145, belong to genetically different subgroups of the same Gla cluster. It is evident that antigenically and genetically diverse forms of JEV cocirculated in a limited area and over a limited period of time. In addition, many live pigs were imported for food into Lao PDR from Vietnam in those days, where G3 had been the major genotype. This might be the possible route and mechanism of expansion.

It is strongly suggested that report of JE cases was underestimated because of absence of good surveillance and accurate laboratory diagnosis $[4,26]$. In this study period of the early 1990s, no epidemic outbreak of JE was observed, and many suspected viral encephalitis cases were with unknown etiology in Lao PDR. This together with seroepidemiological studies [20-22] revealed an endemic but not epidemic status of JE in Lao PDR. The reason why JE epidemic did not occur in Vientiane is unknown, although serologic study in swine showed that JEV activity was not very high, which might suggest low density of vector mosquitoes there [21]. Coexistence of diverse form of JEV might be enabled by very local transmission cycle as a result of this situation.

At present, no specific treatment is available for JE. Work on the production of vaccines using Nakayama, Beijing-1, and SA14-14-2, all members of G3, is ongoing. Although epidemiological evidence of the efficiency of JE vaccine was well reported $[53,54]$, given the recent expansion of G1 in Asia, careful assessments of the efficiency, safety, and validity of ongoing vaccines using G3 strains including SA14-14-2 used in Lao PDR are continuously needed. As JE is easily influenced by environmental and socioeconomic changes, risk assessments from multilateral approaches not only in Asia and Oceania but also Europe and America are required to control the disease.

\section{Conclusion}

Japanese encephalitis remains still one of the public health threats in Asia including Lao PDR. In this study, the subclusters of G1, Gla and G1b, with their own distinct distributions indicate the involvement of different mechanisms and routes of spread and propose that the Australian Gla originated from Southeast Asia through Sunda Island, not from East Asia. Our study also supports the hypothesis that Indochina was the source of JEV transmission to the Asian countries for the both Gla and G1b. In addition, the results together with antigenic and seroepidemiological studies strongly suggest that diverse antigenicity of JEV cocirculated, with endemic pattern in Lao PDR, 1990s.

\section{Conflict of Interests}

The authors declare that there is no conflict of interests regarding the publication of this paper. 


\section{Acknowledgments}

The authors are grateful to the staff of the former National Institute of Health and Epidemiology, Lao People's Democratic Republic, especially the former director Dr. Sithat Insistengmay, and the Department of Virology, Faculty of Medicine, University of the Ryukyus, Japan, especially Dr. Senji Tafuku and Associate Professor Masayuki Tadano, for technical support and valuable suggestions. They also thank the Department of Public Health, Vientiane Municipality, and the Ministry of Public Health, Lao PDR, as well as Okinawa Prefectural Institute of Health and Environment, Japan. This study was conducted as part of the JICA-Lao PHC Project (1992-1999) and was partly supported by the University of the Ryukyus and Grant-in-Aid for Scientific Research (no. 23510030), from the Ministry of Education, Culture, Sports, Science and Technology, Japan. This study was approved by the Ministry of Health, National Ethics Committee for Health Research (no. 017), Lao PDR, and the Ethics Committee for Epidemiological Research (no. 120), Committee for Animal Experiments of the University of the Ryukyus, Okinawa, Japan.

\section{References}

[1] R. T. Johnson, D. S. Burke, M. Elwell et al., "Japanese encephalitis: immunocytochemical studies of viral antigen and inflammatory cells in fatal cases," Annals of Neurology, vol. 18, no. 5, pp. 567-573, 1985.

[2] T. P. Monath and H. X. Heinz, "Flaviviruses," in Fields Virology, B. N. Fields, D. M. Knipe, and P. M. Howley, Eds., vol. 1, pp. 961-1034, Lippincott-Raven, Philadelphia, Pa, USA, 3rd edition, 1996.

[3] J. S. Mackenzie, D. J. Gubler, and L. R. Petersen, "Emerging flaviviruses: the spread and resurgence of Japanese encephalitis, West Nile and dengue viruses," Nature Medicine, vol. 10, no. 12, pp. S98-S109, 2004.

[4] J. S. Mackenzie, D. T. Williams, and D. W. Smith, "Japanese encephalitis virus: the geographic distribution, incidence, and spread of a virus with a propensity to emerge in new areas," in Emerging Virus in Human Population, E. Tabor, Ed., pp. 201268, Elsevier Press, New York, NY, USA, 2007.

[5] R. Doi, A. Shirasaka, M. Sasa, and A. Oya, "Studies on the susceptibility of three species of mosquitoes to Japanese encephalitis virus," Journal of Medical Entomology, vol. 13, no. 4-5, pp. 591-594, 1977.

[6] W.-R. Chen, R. B. Tesh, and R. Rico-Hesse, "Genetic variation of Japanese encephalitis virus in nature," Journal of General Virology, vol. 71, no. 12, pp. 2915-2922, 1990.

[7] W.-R. Chen, R. Rico-Hesse, and R. B. Tesh, "A new genotype of Japanese encephalitis virus from Indonesia," The American Journal of Tropical Medicine and Hygiene, vol. 47, no. 1, pp. 6169, 1992.

[8] T. Solomon, H. Ni, D. W. C. Beasley, M. Ekkelenkamp, M. J. Cardosa, and A. D. T. Barrett, "Origin and evolution of Japanese encephalitis virus in Southeast Asia," Journal of Virology, vol. 77, no. 5, pp. 3091-3098, 2003.

[9] A. J. Schuh, L. Li, R. B. Tesh, B. L. Innis, and A. D. T. Barrett, "Genetic characterization of early isolates of Japanese encephalitis virus: genotype II has been circulating since at least 1951," Journal of General Virology, vol. 91, no. 1, pp. 95-102, 2010.
[10] P. D. Uchil and V. Satchidanandam, "Phylogenetic analysis of Japanese encephalitis virus: envelope gene based analysis reveals a fifth genotype, geographic clustering, and multiple introductions of the virus into the Indian subcontinent," The American Journal of Tropical Medicine and Hygiene, vol. 65, no. 3, pp. 242-251, 2001.

[11] M.-H. Li, S.-H. Fu, W.-X. Chen et al., "Genotype v japanese encephalitis virus is emerging," PLoS Neglected Tropical Diseases, vol. 5, no. 7, Article ID e1231, 2011.

[12] M. A. F. Mohammed, S. E. Galbraith, A. D. Radford et al., "Molecular phylogenetic and evolutionary analyses of Muar strain of Japanese encephalitis virus reveal it is the missing fifth genotype," Infection, Genetics and Evolution, vol. 11, no. 5, pp. 855-862, 2011.

[13] P. T. Nga, M. del Carmen Parquet, V. D. Cuong et al., "Shift in Japanese encephalitis virus (JEV) genotype circulating in Northern Vietnam: implications for frequent introductions of JEV from Southeast Asia to East Asia," Journal of General Virology, vol. 85, no. 6, pp. 1625-1631, 2004.

[14] S.-P. Ma, Y. Yoshida, Y. Makino, M. Tadano, T. Ono, and M. Ogawa, "A major genotype of Japanese encephalitis virus currently circulating in Japan," The American Journal of Tropical Medicine and Hygine, vol. 69, no. 2, pp. 151-154, 2003.

[15] M. Saito, K. Taira, K. Itokazu, and N. Mori, "Recent change of the antigenicity and genotype of Japanese encephalitis viruses distributed on Okinawa Island, Japan," The American Journal of Tropical Medicine and Hygiene, vol. 77, no. 4, pp. 737-746, 2007.

[16] H. Y. Wang, T. Takasaki, S. H. Fu et al., "Molecular epidemiological analysis of Japanese encephalitis virus in China," Journal of General Virology, vol. 88, no. 3, pp. 885-894, 2007.

[17] Y.-J. Chung, J.-H. Nam, S.-J. Ban, and H.-W. Cho, "Antigenic and genetic analysis of Japanese encephalitis viruses isolated from Korea," American Journal of Tropical Medicine and Hygiene, vol. 55, no. 1, pp. 91-97, 1996.

[18] W.-F. Tang, M. Ogawa, Y. Eshita, H. Aono, and Y. Makino, "Molecular evolution of Japanese encephalitis virus isolates from swine in Oita, Japan during 1980-2009," Infection, Genetics and Evolution, vol. 10, no. 2, pp. 329-336, 2010.

[19] T. Okuno, "An epidemiological review of Japanese encephalitis," World Health Statistics Quarterly, vol. 31, no. 2, pp. 120-133, 1978.

[20] T. Fukunaga, B. Phommasack, K. Bounlu et al., "Epidemiological situation of dengue infection in Lao P.D.R," Tropical Medicine, vol. 35, no. 4, pp. 219-227, 1993.

[21] Y. Makino, M. Saito, B. Phommasack et al., "Arbovirus infections in pilot areas in Laos," Tropical Medicine, vol. 36, no. 4, pp. 131-139, 1995.

[22] P. Vongxay, Y. Makino, K. Kanemura, M. Saito, and T. Fukunaga, "Seroepidemiological study of arbovirus infection in Khammouane Province, Lao PDR," Ryukyu Medical Journal, vol. 15, no. 1, pp. 19-22, 1995.

[23] J. Vallée, A. Dubot-Pérès, P. Ounaphom, C. Sayavong, J. E. Bryant, and J.-P. Gonzalez, "Spatial distribution and risk factors of dengue and Japanese encephalitis virus infection in urban settings: the case of Vientiane, Lao PDR," Tropical Medicine \& International Health, vol. 14, no. 9, pp. 1134-1142, 2009.

[24] A. Hiscox, C. H. Winter, P. Vongphrachanh et al., "Serological investigations of flavivirus prevalence in Khammouane Province, Lao People's Democratic Republic, 2007-2008," The American Journal of Tropical Medicine and Hygine, vol. 83, no. 5, pp. 1166-1169, 2010.

[25] J. V. Conlan, K. Vongxay, R. G. Jarman et al., "Serologic study of pig-associated viral zoonoses in Laos," The American Journal 
of Tropical Medicine and Hygiene, vol. 86, no. 6, pp. 1077-1084, 2012.

[26] T. E. Erlanger, S. Weiss, J. Keiser, J. Utzinger, and K. Wiedenmayer, "Past, present, and future of Japanese encephalitis," Emerging Infectious Diseases, vol. 15, no. 1, pp. 1-7, 2009.

[27] C. E. Moore, S. D. Blacksell, T. Taojaikong et al., "A prospective assessment of the accuracy of commercial IgM ELISAs in diagnosis of Japanese encephalitis virus infections in patients with suspected central nervous system infections in Laos," The American Journal of Tropical Medicine and Hygiene, vol. 87, no. 1, pp. 171-178, 2012.

[28] T. Nabeshima, H. T. K. Loan, S. Inoue et al., "Evidence of frequent introductions of Japanese encephalitis virus from south-east Asia and continental east Asia to Japan," Journal of General Virology, vol. 90, no. 4, pp. 827-832, 2009.

[29] F. Aubry, M. Vongsouvath, A. Nougairède et al., "Complete genome of a genotype I Japanese encephalitis virus isolated from a patient with encephalitis in Vientiane, Lao PDR," Genome Announcements, vol. 1, no. 1, Article ID e00157-12, 2013.

[30] M. Saito, T. Sunagawa, Y. Makino et al., "Three Japanese encephalitis cases in Okinawa, Japan, 1991," Southeast Asian Journal of Tropical Medicine and Public Health, vol. 30, no. 2, pp. 277-279, 1999.

[31] A. Ali and A. Igarashi, "Antigenic and genetic variations among Japanese encephalitis virus strains belonging to genotype 1," Microbiology and Immunology, vol. 41, no. 3, pp. 241-252, 1997.

[32] K. Bundo, K. Morita, and A. Igarashi, "Enzyme-linked immunosorbent assay (ELISA) on Japanese encephalitis virus. III. Assay on antibody titers in swine sera," Tropical Medicine, vol. 24, no. 2, pp. 87-102, 1982.

[33] A. Igarashi, P. Chiowanich, P. Leechanachai, and J. Supawadee, "Virological and epidemiological studies on encephalitis in Chiang Mai Area, Thailand, in the year of 1982. III. Virus isolation from clinical materials," Tropical Medicine, vol. 25, no. 3, pp. 149-154, 1983.

[34] K. Morita, M. Tadano, S. Nakaji et al., "Locus of a virus neutralization epitope on the Japanese encephalitis virus envelope protein determined by use of long PCR-based region-specific random mutagenesis," Virology, vol. 287, no. 2, pp. 417-426, 2001.

[35] J. D. Thompson, T. J. Gibson, F. Plewniak, F. Jeanmougin, and D. G. Higgins, "The CLUSTAL X windows interface: flexible strategies for multiple sequence alignment aided by quality analysis tools," Nucleic Acids Research, vol. 25, no. 24, pp. 48764882, 1997.

[36] G. Perrière and M. Gouy, "WWW-query: an on-line retrieval system for biological sequence banks," Biochimie, vol. 78, no. 5, pp. 364-369, 1996.

[37] H. Tsuchie, K. Oda, I. Vythilingam et al., "Genotypes of Japanese encephalitis virus isolated in three states in Malaysia," The American Journal of Tropical Medicine and Hygiene, vol. 56, no. 2, pp. 153-158, 1997.

[38] N. Nitatpattana, A. Dubot-Pérès, M. A. Gouilh et al., "Change in Japanese encephalitis virus distribution, Thailand," Emerging Infectious Diseases, vol. 14, no. 11, pp. 1762-1765, 2008.

[39] X. Gao, H. Liu, H. Wang, S. Fu, Z. Guo, and G. Liang, "Southernmost Asia is the source of Japanese encephalitis virus (genotype 1) diversity from which the viruses disperse and evolve throughout Asia," PLoS Neglected Tropical Diseases, vol. 7, no. 9, Article ID e2459, 2013.
[40] J.-H. Huang, T.-H. Lin, H.-J. Teng et al., "Molecular epidemiology of Japanese encephalitis virus, Taiwan," Emerging Infectious Diseases, vol. 16, no. 5, pp. 876-878, 2010.

[41] A. Sarkar, D. Taraphdar, S. K. Mukhopadhyay, S. Chakrabarti, and S. Chatterjee, "Molecular evidence for the occurrence of Japanese encephalitis virus genotype I and III infection associated with acute encephalitis in patients of West Bengal, India, 2010," Virology Journal, vol. 9, article 271, 2012.

[42] P. V. Fulmali, G. N. Sapkal, S. Athawale, M. M. Gore, A. C. Mishra, and V.P. Bondre, "Introduction of Japanese encephalitis virus genotypei, India," Emerging Infectious Diseases, vol. 17, no. 2, pp. 319-321, 2011.

[43] S. P. Chen, "Molecular phylogenetic and evolutionary analysis of Japanese encephalitis virus in China," Epidemiology and Infection, vol. 140, no. 9, pp. 1637-1643, 2012.

[44] Y. X. Li, M. H. Li, S. H. Fu et al., "Japanese encephalitis, Tibet, China," Emerging Infectious Diseases, vol. 17, no. 5, pp. 934-936, 2011.

[45] H. Hasegawa, M. Yoshida, Y. Kobayashi, and S. Fujita, "Antigenic analysis of Japanese encephalitis viruses in Asia by using monoclonal antibodies," Vaccine, vol. 13, no. 17, pp. 1713-1721, 1995.

[46] World press org, The partnership for the East AsianAustralasian Flyway, 2013, http://www.eaaflyway.net/.

[47] Jelsoft Enterprises Ltd, 2000, http://www.flutrackers.com/ forum/showthread.php? $\mathrm{t}=147$.

[48] J. S. Mackenzie, C. A. Johansen, S. A. Ritchie, A. F. van den Hurk, and R. A. Hall, "Japanese encephalitis as an emerging virus: the emergence and spread of Japanese encephalitis virus in Australasia," Current Topics in Microbiology and Immunology, vol. 267, pp. 49-73, 2002.

[49] S. A. Ritchie and W. Rochester, "Wind-blown mosquitoes and introduction of Japanese encephalitis into Australia," Emerging Infectious Diseases, vol. 7, no. 5, pp. 900-903, 2001.

[50] K. Morita, "Molecular epidemiology of Japanese encephalitis in East Asia," Vaccine, vol. 27, no. 50, pp. 7131-7132, 2009.

[51] L. Rosen, "Natural history of Japanese encephalitis virus," Annual Review of Microbiology, vol. 40, pp. 395-414, 1986.

[52] M. Saito, T. Ito, Y. Amano et al., "Trials for risk assessment of Japanese encephalitis based on serologic surveys of wild animals," in Flavivirus encephalitis, D. Růžek, Ed., pp. 427-438, InTech, 2011.

[53] C. H. Hoke, A. Nisalak, N. Sangawhipa et al., "Protection against Japanese encephalitis by inactivated vaccines," The New England Journal of Medicine, vol. 319, no. 10, pp. 608-614, 1988.

[54] M. B. Bista, M. K. Banerjee, S. H. Shin et al., "Efficacy of singledose SA 14-14-2 vaccine against Japanese encephalitis: a case control study," The Lancet, vol. 358, no. 9284, pp. 791-795, 2001. 


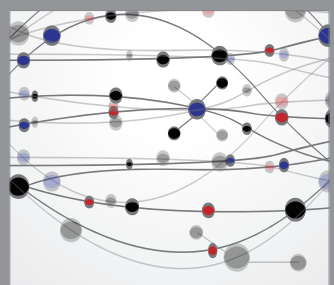

The Scientific World Journal
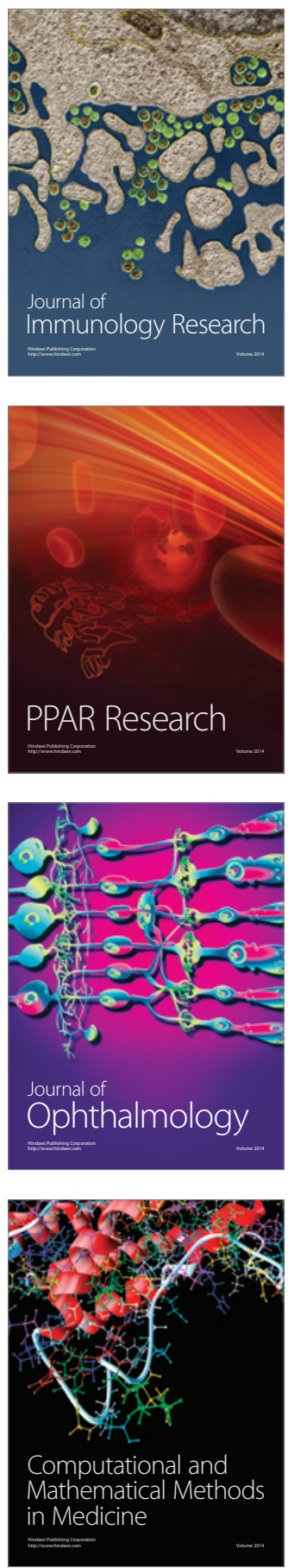

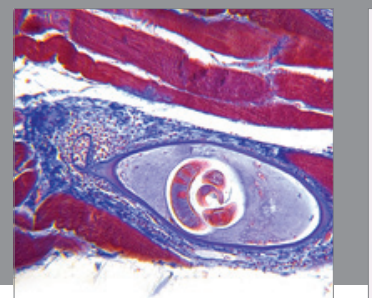

Gastroenterology

Research and Practice
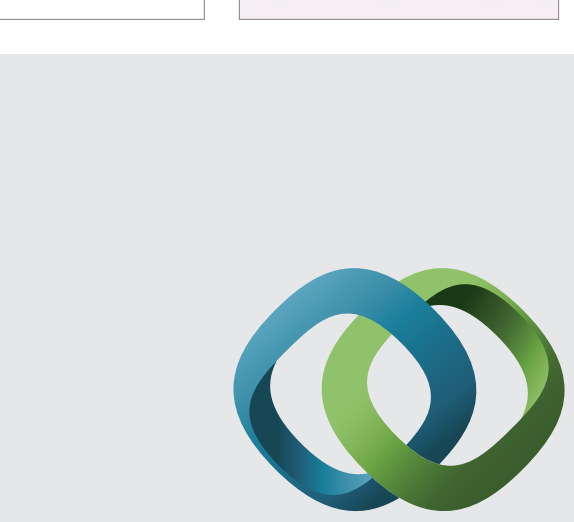

\section{Hindawi}

Submit your manuscripts at

http://www.hindawi.com
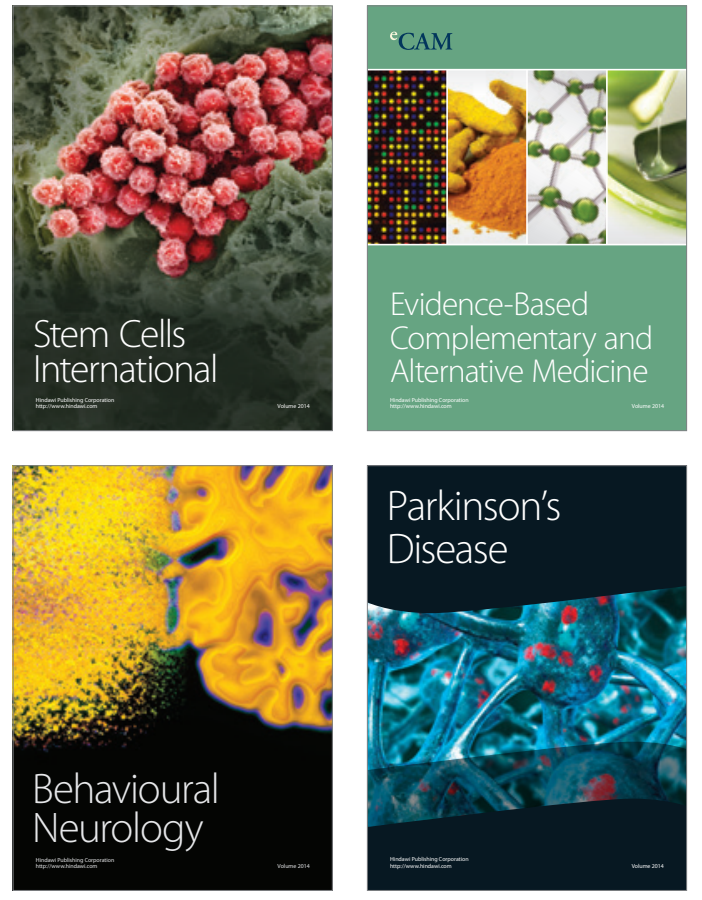
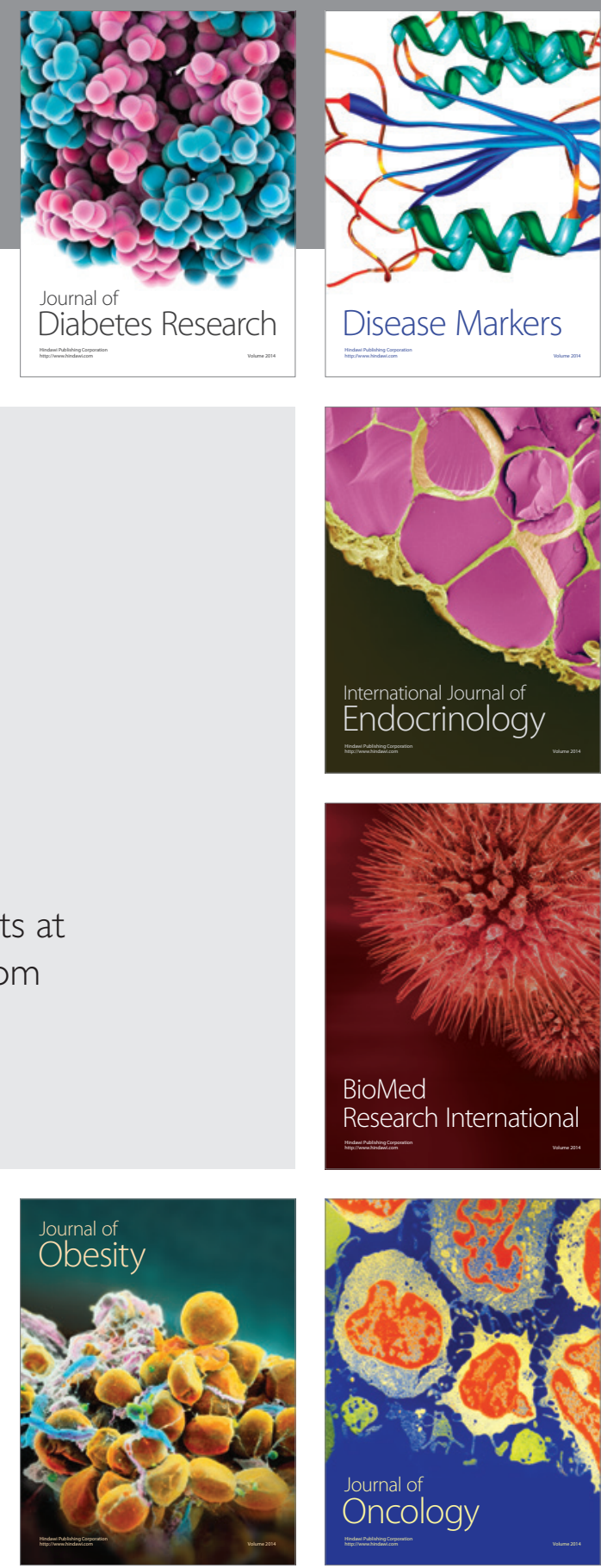

Disease Markers
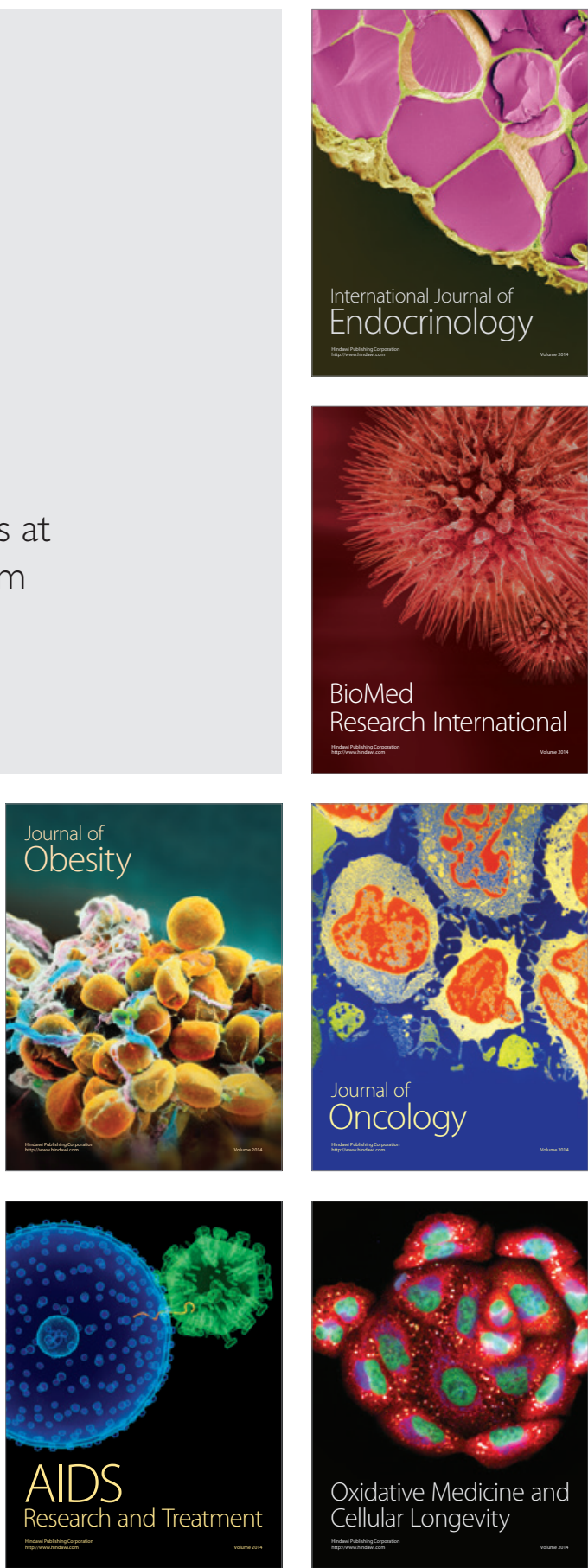